\title{
Cognition and behavior in context: a framework and theories to explain natural resource use decisions in social-ecological systems
}

\author{
S. M. Constantino $0^{1,2,5}$ (D) M. Schlüter ${ }^{3} \cdot$ E. U. Weber ${ }^{1,2,4} \cdot$ N. Wijermans ${ }^{3}$
}

Received: 3 June 2020 / Accepted: 20 May 2021 / Published online: 3 July 2021

(c) The Author(s) 2021

\begin{abstract}
The complex, context-dependent, and dynamic nature of human behavior is increasingly recognized as both an important cause of sustainability problems and potential leverage for their solution. Human beings are diverse, as are the social, ecological, and institutional settings in which they are embedded. Despite this recognition and extensive knowledge about human decision-making in the behavioral sciences, empirical analysis, formal models, and decision support for sustainability policy in natural resource management often either neglect human behavior or are based on narrow and overly simplistic assumptions. Integrating insights from behavioral sciences into sustainability research and policy remains a challenge. This is in part due to the abundance and fragmentation of theories across the social sciences and in part the challenges of translating research across disciplines. We provide a set of tools to support the integration of knowledge about human behavior into empirical and model-based sustainability research. In particular, we (i) develop a process-oriented framework of embedded human cognition (Human Behavior-Cognition in Context or HuB-CC), (ii) select an initial set of 31 theories with the potential to illuminate behavior in natural resource contexts and map them onto the framework, and (iii) suggest pathways for using the framework and mapping to encourage trans-disciplinary investigations, identify and compare theories, and facilitate their integration into empirical research, formal models, and ultimately policy and governance for sustainability. Our theory selection, framework, and mapping offer a foundation-a "living" platform—upon which future collaborative efforts can build to create a resource for scholars and practitioners working at the intersection of social sciences and natural resource management.
\end{abstract}

Keywords Social-ecological system $\cdot$ Behavior $\cdot$ Cognition $\cdot$ Framework $\cdot$ Social science $\cdot$ Embedded cognition

Handled by Jeremy Brooks, Ohio State University School of Environment and Natural Resources, United States.

S. M. Constantino

Sara.constantino@gmail.com

N. Wijermans

nanda.wijermans@su.se

1 School for Public and International Affairs, Princeton University, Princeton, NJ, USA

2 Andlinger Center for Energy and the Environment, Princeton University, Princeton, NJ, USA

3 Stockholm Resilience Center, Stockholm University, Stockholm, Sweden

4 Department of Psychology, Princeton University, Princeton, NJ, USA

51504 Pacific St, Apt. 3, Brooklyn, NY 11213, USA

\section{Introduction}

The need to account for the complex, context-dependent, and dynamic nature of decision making and behavior in collective action problems and governance of social-ecological systems (SES) is increasingly recognized (Weber and Johnson 2009; Fulton et al. 2011; Victor 2015; Beckage et al. 2018; Schill et al. 2019). Human behavior is a key source of uncertainty in natural resource use (e.g. in fisheries, Fulton et al. 2011) and an important determinant of both local and global sustainability challenges (Beckage et al. 2018). Changing human behavior is a critical challenge for sustainability transitions, and in certain contexts may be more promising than regulatory pathways (Weber 2015; Nyborg et al. 2016). Despite this awareness, and a growing body of knowledge on human decision-making in the behavioral sciences, nuanced views of human behavior remain relatively under-explored in SES research. Instead, tools (such 
as cost-benefit analysis) used for decision support in natural resource management are still largely based on assumptions associated with rational choice theory (Groeneveld et al. 2017). The lack of more realistic conceptualizations of human behavior is in part due to translational hurdles between disciplines, which can pose challenges for the identification and incorporation of complex human motivations and behaviors into SES investigations. Even in the behavioral sciences, knowledge about human behavior is fragmented across subfields and often specific to particular behaviors or contexts (Schlüter et al. 2017). Here, we (1) provide a framework of embedded decision-making that describes and integrates key concepts from major themes studied in cognitive psychology, (2) select a relevant and illustrative initial set of theories from the social and behavioral sciences and map them onto the framework and (3) suggest different pathways through which the framework in combination with the mapping of theories can help inform theory selection, analysis of human behavior in empirical contexts and the development of social-ecological models. This work is intended as an organizing and synthesizing tool and platform for further cross-disciplinary research, and as such is a "living" project.

\section{Cognition and behavior in social-ecological systems}

To account for natural resource use behaviors, which vary across individuals and contexts, requires theories of how behavior depends on structural features of a particular situation, including the social, physical, institutional and economic context (Weber and Johnson 2009). Sustainability challenges are generally characterized by high uncertainty about future outcomes, long time horizons, and deferred and diffuse costs and benefits (Weber 2015). They are also often social dilemmas that require collective action and have pronounced intergenerational implications. In these uncertain and changing environments, decisions are often made with limited information and require continual learning and adaptation. In such settings, humans look to their surroundings, from social norms to existing power dynamics (Peattie 2010) and to regulatory frameworks, to resolve uncertainty and conflicting interpretations (March 1994). Here, we focus primarily on natural resource use decisions and human behavior in SES. Specifically, we consider individuals to be embedded in a system of social, institutional, and ecological relations. Cognition and behavior emerge from these complex interactions, and thus must be understood in context - the framework and theories that we discuss below go some way towards accounting for unexpected responses to rules, regulations, and regime shifts (see Supplementary Material SM-A for a list of observed behavioral patterns in natural resource use contexts solicited from an informal survey of SES researchers).
A pattern that is often observed in fisheries and agriculture is 'non-optimal' time-allocation decisions. Fishers or farmers continue extracting resources even when they are no longer profitable (delayed exit) or quit resource extraction while profits could still be made (premature exit, or satisficing) (Constantino and Daw 2015). Individuals more generally tend to prioritize present over future outcomes at very high rates (Laibson 1997). These resource-use decisions can be rationalized by taking the full scope of cognitive and contextual constraints into account. For example, financial or institutional constraints can result in behavior that appears myopic. Families buy firewood for cooking on a daily basis, despite having access to a gas cooker with less expensive fuel, because filling the gas bottle requires an upfront monthly purchase (Bansal et al. 2013). However, they may also be driven by goals other than profit-maximization. They may approach the problem emotionally, and with imperfect information. Their decisions may also depend on social, institutional, economic, and ecological relations. Indeed, in most natural resource use contexts, individuals are embedded in a system of social and institutional relations, and the position of an individual in a network or community can play an important role, leading at times to the prioritization of behaviors that strengthen social relations rather than increasing profits. For example, a fisher may take risks that seem unnecessary from the perspective of resource exploitation, but that increase their reputation or status in the community; or, they may decide to sell fish at a particular price to a particular buyer to maintain social relations, even at an economic cost.

In fact, social norms and conventions as well as structural conditions can determine an individual's position in a social hierarchy through constructs such as age, gender, race, or ethnicity, which may limit or amplify agency and dictate power relations. For example, women from the Swahili coast have, for generations, fished octopus - an activity that aligns with culturally sanctioned gender roles. This also means that in general they stay close to shore and do not learn to swim or to operate boats (indeed, their presence on boats is thought to bring bad luck) (O'Neill 2017). Cultural beliefs and practices thus define their operating space in society and limit the type of work they can do. Informal institutions or social norms can create expectations about how different types of people should behave. These expectations are in turn reinforced and spread through social networks. Social networks, which describe how different actors are connected to each other, are an important source of information and opportunities-they create social capital. While some communities and individuals are linked to many others, some are relatively isolated, which may, in turn, limit their access to resources. For example, women in the Ghanaian tuna industry occupy a unique and important niche in a maledominated industry — they work as intermediaries, financing 
fishing expeditions, which gives them access to a large share of the catch (O'Neill et al. 2018). The position of an individual in a network can have widespread repercussions for individual and collective behavior. The personal history of interactions with peers can also influence perceptions and behaviors, and this history of interactions can spillover to novel situations with different individuals. For example, if a group of fishers has successfully cooperated to build a well, they are more likely to become a successful fishing cooperative (Basurto et al. 2013), suggesting positive spillovers and path dependencies in cooperative behaviors. These examples highlight the institutional, cultural, and social contexts in which actors are embedded.

Individuals are also embedded in systems of ecological relations. The ecological context poses additional constraints and opportunities, shapes emotions, values, and practices, and is in turn shaped by them through a process of coevolution (von Heland and Folke 2014; Schill et al. 2019). Ecological contexts are characterized by different risk profiles and visibility or fidelity of signals about the state of natural resources. Uncertainty about the state of natural resources can contribute to overharvesting or other unsustainable natural resource use decisions. Feedback from the environment can be lagged or can mask the underlying reality, obscuring information about changing resource availability. For example, a consumer may not notice the precarity of a fish species due to its availability, or the availability of similar species, in stores at constant prices (Crona et al. 2015). Ecological contexts also shape people's emotions, goals, and values, e.g. what people care about and what motivates them to engage in solving sustainability issues (Masterson et al. 2017), and afford certain behaviors over others (Kaaronen 2017). The ecological context may thus also shape prepotent or habitual responses by cueing certain affective states.

These observations from the field illustrate several themes: people face imperfect knowledge and learn dynamically from noisy and changing environments; they use multiple decision-making processes and have diverse goals and incentives; their decisions are intertwined and co-evolve with features of the broader social-ecological context; specific features of the biophysical and social context can activate a small relevant subset of goals, values, emotions, and norms (from among a larger latent set of such characteristics), which guide and influence actions. Despite the fact that casebased knowledge in SES research takes into account contextual factors in individual and collective action and considers people to be embedded in social and biophysical environments (Reyers et al. 2018), it rarely makes explicit how this interdependence affects human decision making and behavior (Masterson et al. 2017). Recent efforts in this direction draw on theories such as sense of place (Masterson et al. 2017), affordance theory (Raymond et al. 2018), or embodied cognition (Hukkinen 2014). Economic theory, which is pervasive across many disciplines, including sustainability science, tends to model decision-making as independent of context. This simplifying assumption greatly enhances generalizability but requires substantial abstraction, and in the case of natural resource use decisions may miss nuances that are important for describing behavior and predicting policy outcomes. Across other social sciences, analyses of human behavior fall along a spectrum from highly contextualized to abstract. The diversity of approaches and foci of existing theories creates challenges for their integration into SES and policy design considerations.

\section{Human behavior-cognition in context}

To make this exercise manageable, we limit our examples and applications to decision-making about natural resource use, though we believe our tools will be applicable beyond such circumscribed behaviors. This includes decisions such as whether, when, where, and how to extract a natural resource such as fish or plan for a specific crop. The HuBCC (Human Behavior-Cognition in Context) framework was informed by the MoHuB framework (Modelling Human Behaviour, Schlüter et al. 2017) but presents a significant departure from this initial effort. HuB-CC is aimed not only at modelers but also researchers and practitioners doing empirical and applied work. It was developed with psychologists and captures fundamental features and processes underlying perception, judgment, and decision-making. The addition of "Cognition in Context" emphasizes the framework's attempt to describe cognitive processes situated in a broader social and biophysical environment-and is an important step in creating the bridge between cognitive psychology and SES research. Process-based accounts of behavior allow for a more nuanced appreciation of heterogeneity across context and individuals and more accurate predictions of decisions in response to changes in the environment. They also point to a broader range of entry points for policy interventions.

\section{Overview of the paper}

In "Historical perspective: human cognition and behavior research," we thus begin with a broad overview of some trends and themes that have emerged from behavioral science research. In "Methods" and "HuB-CC framework and theory selection," we introduce a set of tools for organizing and contrasting relevant theories from across the social and behavioral sciences-a framework of embedded cognition and behavior and an initial selection of prominent theories of individual decision-making, which may offer insights into some of the behavioral patterns identified by SES research. In "Using the framework and theory map," we demonstrate two use cases for these tools in applied SES research, though one of their primary functions is in 
stimulating cross- and trans-disciplinary conversations and collaborations. This paper provides a scaffolding for integrating more diverse and realistic conceptions of human behavior in theoretical, modeling, and empirical work in SES, with the ultimate aim of enriching policy analysis and development.

\section{Historical perspective: human cognition and behavior research}

Over the past 50 years, there has been a proliferation of often piecemeal theories of human behavior from psychology, behavioral economics, sociology, political science, anthropology, and ecology, that run the gamut from vague to specific, informal to formal, descriptive to normative, and qualitative to quantitative. The sheer quantity of theories can make them difficult to identify and evaluate. In this section, we try to impose some helpful order and guidance by identifying four classes of theories that depart from traditional rational choice in particular ways. This is not intended as a comprehensive account of all social science theories, but rather an overview of important trends and themes that have emerged from various disciplines. In general, these theories extend classic models of utility-maximization, which tend to assume that people are self-interested, have full information about the world, and have infinite time and capacity to decide on the best action. Below we provide a brief description of four types of departures or extensions of these models: (i) cognitive and emotional constraints (Simon 1957), (ii) multiple goals and processes (Maslow 1943; Hilgard 1987), (iii) preference and decision dynamics or learning (Rescorla et al. 1972) and (iv) cognition in broader contexts (e.g. social, political, ecological) (Ostrom 1990; March 1997).

\section{Cognitive and emotional constraints}

Early research on human perception identified that perception and decision-making are relative, i.e., they depend on previous experience, baselines, and context. The WeberFechner law (1860) describes how perception depends on context. For example, when an initial sound is low, a small increase is registered by a human listener as "noticeably louder," whereas a much larger increment is needed when the baseline tone is loud to begin with. More recently, Weber (2003) described the importance of reference points for a broad set of judgments, including those related to perceived risk. The relative encoding of value (i.e. reference-dependence) is a central feature of prospect theory (Kahneman and Tversky 1979), an empirically-driven extension of expected utility theory that won the authors the Nobel Memorial Prize in Economic Sciences, and which we describe in more detail below.

Such reference or context-dependence can be seen as the consequence of cognitive and emotional constraints (Simon 1957). Homo economicus may be omniscient, but homo sapiens do not have access to full information about choice options and their consequences and so must often learn through experience and act with only partial information. Even when full information is available in principle, finite attention and information processing capacity and limited time resources have to be allocated judiciously and necessitate a tradeoff between desired accuracy and effort or other choice objectives (Payne et al. 1992). Some economic approaches address these limitations with constrained optimization models, including models of rational inattention (Sims 2006). These models however do not fully explain the ever-growing ways in which human information processing is content and context-specific (see, e.g. Camerer, 1998; Weber and Johnson, 2009).

Two prominent psychological theories-prospect theory and query theory_directly describe the relative encoding and sequential processing of choice options, respectively. Prospect theory (Kahneman and Tversky 1979), which gained traction in the 1980s, retains the basic features of expected utility theory but introduces the notion of a reference point relative to which new events are evaluated, evoking Weber's law (1834). Query theory employs attentional and memory processes to account for the behavioral patterns that Prospect Theory describes through functional regularities, e.g., a value function that is split into loss and a gain domain relative to a reference point (Johnson et al. 2007; Weber et al. 2007).

\section{Multiplicity of goals and processes}

Outside of traditional economics or evolutionary theory, behavior is thought to be motivated by a multiplicity of goals, which may be aligned or in conflict but are not exclusively aimed at material gains or fitness maximization (in the narrow sense). Taxonomies of human needs-in sociology (Weber 1919), philosophy (Habermas 1987), and psychology (Maslow 1943; Hilgard 1987)—include individual goals (related to self-preservation and procreation) but also social, spatial or physical desires (feeling connected to a group or countryside) and meta-cognitive goals (feeling confident or in control).

Multiple goals can, in turn, be achieved through a multiplicity of processes (Weber et al. 2005; Weber and Lindemann 2007). Dual-process theories, which distinguish between implicit, automatic, unconscious, affective processes and explicit, controlled, conscious, reason-based processes (Kahneman et al. 2002), have gained particular traction. Other frameworks posit three types of processing 
modes: calculation-based, emotion- or affect-based, and role- or rule-based mode (Weber and Lindemann 2007). The use of a specific decision mode can influence the outcome of the decision in both the lab (Krosch et al. 2012) and the field (Reeck et al. 2018), and the mode that is activated varies with the decision domain and context (Weber et al. 2005; Weber and Lindemann 2007). For example, when making financial decisions, people are likely to adopt a calculationbased mode, explicitly trading off costs and benefits (Weber and Lindemann 2007), whereas they are likely to adopt a role or rule-based mode when deciding on matters related to personal identity.

Perception and decision-making often vary for the same individual across contexts. Such context-sensitive behavior arises when decision-makers use features of the internal and external environment to make adequate decisions with less processing capacity while managing diverse goals that also become more or less salient depending on the context (Bettman 1979; Payne et al. 1992; Lieder and Griffiths 2019). As a result, behavior may appear inconsistent from one situation or time period to the next and may demonstrate path dependencies - that is, future decisions may depend on what has come before. Accounting for this variation requires a theory of how behavior depends on context. The assumption that specific physical or social features of a particular situation temporarily activate a subset of situational characteristics (values, goals, beliefs, etc.) from the much larger set of stable and latent characteristics is an important component of the HuB-CC framework.

\section{Preference and decision dynamics}

The acknowledgment of multiple goals and processes leads to the questions of when and why certain goals or processes take precedence. Actions and preferences are context-specific - dependent on internal or external states - and are often constructed or learned over time. The emphasis on learning is particularly relevant in novel or changing environments where actors do not have perfect or complete information. In these situations, actors make choices while simultaneously updating their expectations and their representations of the environment as they encounter new data. Learning theories describe the process by which a preference for one action over another is constructed, depending on context, experience or social information. For example, reinforcement learning models, an area of machine learning and control theory, have been adapted in various ways to describe human learning in novel environments (Rescorla et al. 1972; Dayan and Daw 2008). In these models, an individual with imperfect knowledge of an environment samples the environment through a balance of exploration (of novel information) and exploitation (of current knowledge). Reinforcement learning can be model-based or model-free.
In model-based learning, the actor learns an abstract model of the structure of the environment which can facilitate planning and rapid responses to changing contingencies (Gläscher 2010). In model-free learning, experience is used directly and iteratively to shape associations between behaviors and outcomes. In a static environment, exploitation allows an individual to use existing knowledge to extract resources, while novel information obtained through exploration allows the individual to learn about potentially better resources. Both generate a reward prediction error, which is used to update the current representation of the environment and adjust behaviors accordingly. In this sense, desirable behaviors are learned over time, constantly adjusting to the local context, and dependent on past experiences.

\section{Cognition in broader context}

The previous three classes of theories all touch on the importance of context or the broader social and biophysical environment for decision-making. There is ample evidence that humans are social creatures whose decisions are highly influenced by the behavior of others and by broader social and cultural norms. Social conformity, which is supported by reputational concerns, mimicry or the threat of sanctions among other factors, can result in nonlinear processes, whereby endogenous social change can accelerate (social tipping) or delay (social inertia) collective action (Nyborg et al. 2016). This embeddedness of behavior extends beyond the social context to the institutional, economic and biophysical environment. Context determines what is salient, or which values and norms are cued at any given moment. This has led psychologists to distinguish between stable or slowly evolving characteristics (latent goals, values, preferences etc.) and situational characteristics that get temporarily activated by different situations or contexts. In psychology, the interdependence of the individual with the broader environment has been studied under the general theory of affordances (Gibson 1979) and more recently under the theory of embodied cognition (Varela et al. 1991). In behavioral economics, choice architecture-the intentional organization or design of the environment to influence behavior (Johnson et al. 2012) - highlights the strategic shaping of the environment as a policy tool. In sociology and institutional economics, the focus has tended towards the social and institutional structures that shape individual and collective decision making, from theories about social networks to social norms to organizational behavior (Granovetter 1985, 2005; Ostrom 1990; March and Olsen 1996; March 1997; Bicchieri 2006).

This four-part classification of recent theoretical developments in the behavioral and social sciences offers a complementary perspective to other syntheses of this literature (Mellers et al. 1998; Kahneman 2003; Weber and Johnson 2009). Whereas most previous summaries of this 
body of literature have focused on the deficits and cognitive and emotional "constraints" of boundedly-rational decision-makers, our summary balances this view with a narrative of "abundance," focusing on the diversity of goals and processes underlying decision making, and focusing on decision making in dynamic environments and in richer social, institutional and ecological contexts. These broad trends inform the types of processes, behaviors, and theories we had in mind as we developed the tools presented in the subsequent sections of this paper.

\section{Methods}

In this section, we describe the development of the HuB$\mathrm{CC}$ framework (Fig. 1), theory selection, and mapping of theories onto the framework (Theory Map; Table 1 and Supplementary Material SM-B.B1). This was an iterative processes, guided by cognitive models of human perception and decision-making, the historical themes identified in "Historical perspective: human cognition and behavior research" and behavioral patterns from SES field studies that are not easily captured by rational choice theory (see Supplementary Material SM-A for details). The mapping of the theories onto the framework is one method of organizing and comparing theories by drawing attention to the cognitive processes underlying central features of these theories. It further situates these theories in a framework of embedded cognition-bridging cognition, behavioral theories, and SES research.

\section{Framework}

HuB-CC was developed by extending MoHuB (Schlüter et al. 2017), an existing framework developed by and for SES modelers to facilitate the inclusion of behavioral theories in the design of formal social-ecological models (Schlüter et al. 2017). The elements of the original MoHoB framework were selected to be useful for the development of agent-based models. The purpose of HuB-CC is broader, serving the needs of modelers but also empirical or experimental SES researchers and practitioners. The development of HuB-CC was grounded in knowledge about perception and decision making from cognitive psychology. HuB-CC includes general cognitive processes that go some way towards accounting for human behavior in diverse settings, as such different components can be linked to aspects of theories of human behavior, though not all theories specify cognitive processes (see "Mapping of theories onto the framework" below). Note that Hub-CC is a framework, i.e., a set of concepts that are relevant for explaining observed outcomes (McGinnis 2011), not itself a theory or a model. In "A process-based framework for behavior in SES," we describe the elements and processes that comprise $\mathrm{HuB}-\mathrm{CC}$.
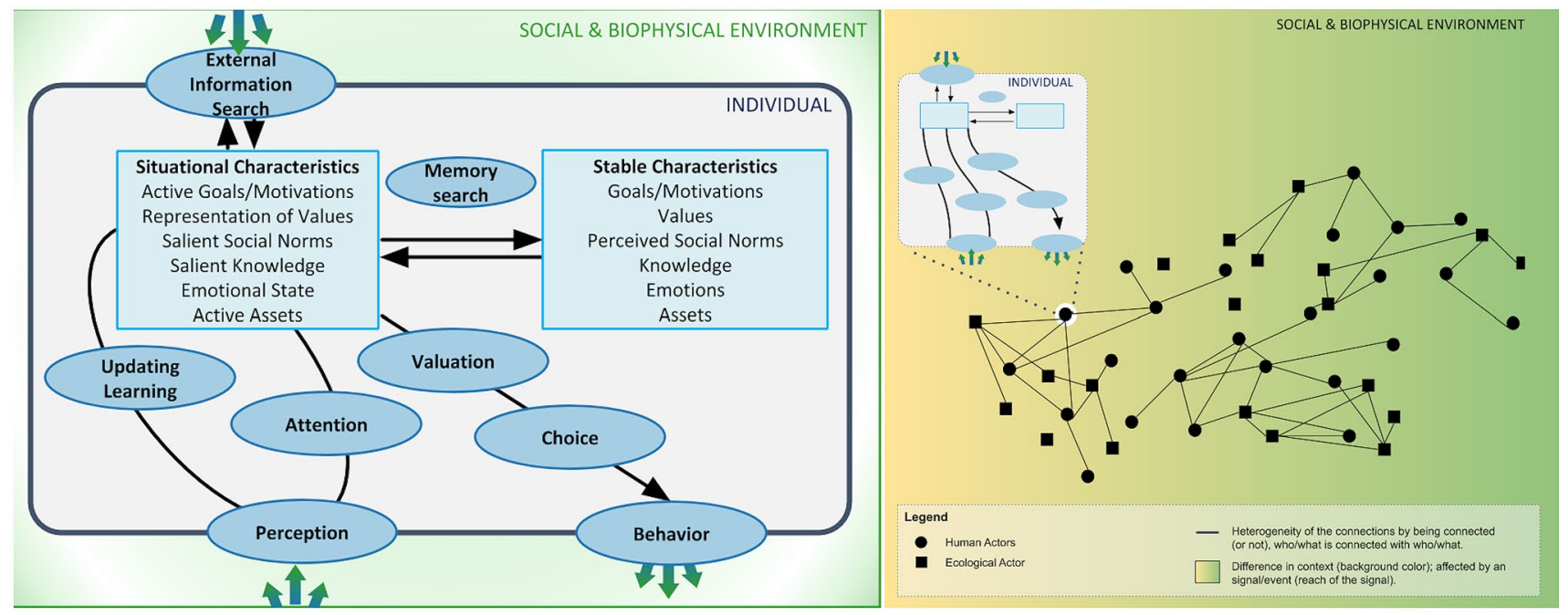

Fig. 1 HuB-CC framework. (Left) A cognitive-social-ecological framework reflecting key characteristics (squares) and processes (ovals) thought to underlie human behavior and perception. In this framework, the actor is situated in an expanded social and biophysical environment. (Right) An individual actor is embedded in a network of connections (lines) between social (circles) and ecological (squares) actors. The network is embedded in a broader social (includes economics, politics, institutions, culture, norms) and biophysical environment. The context varies for different actors (represented by the color gradient) 


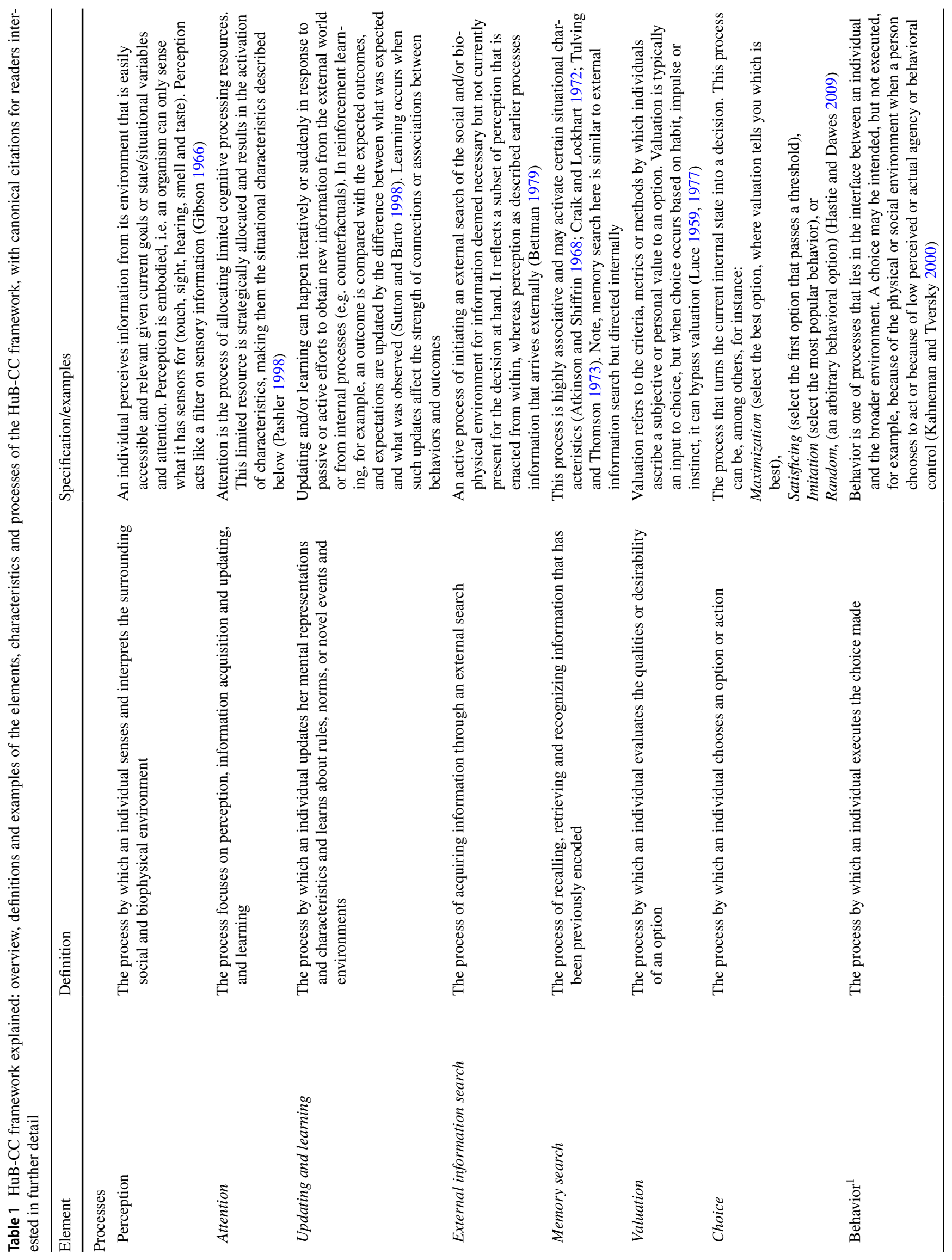




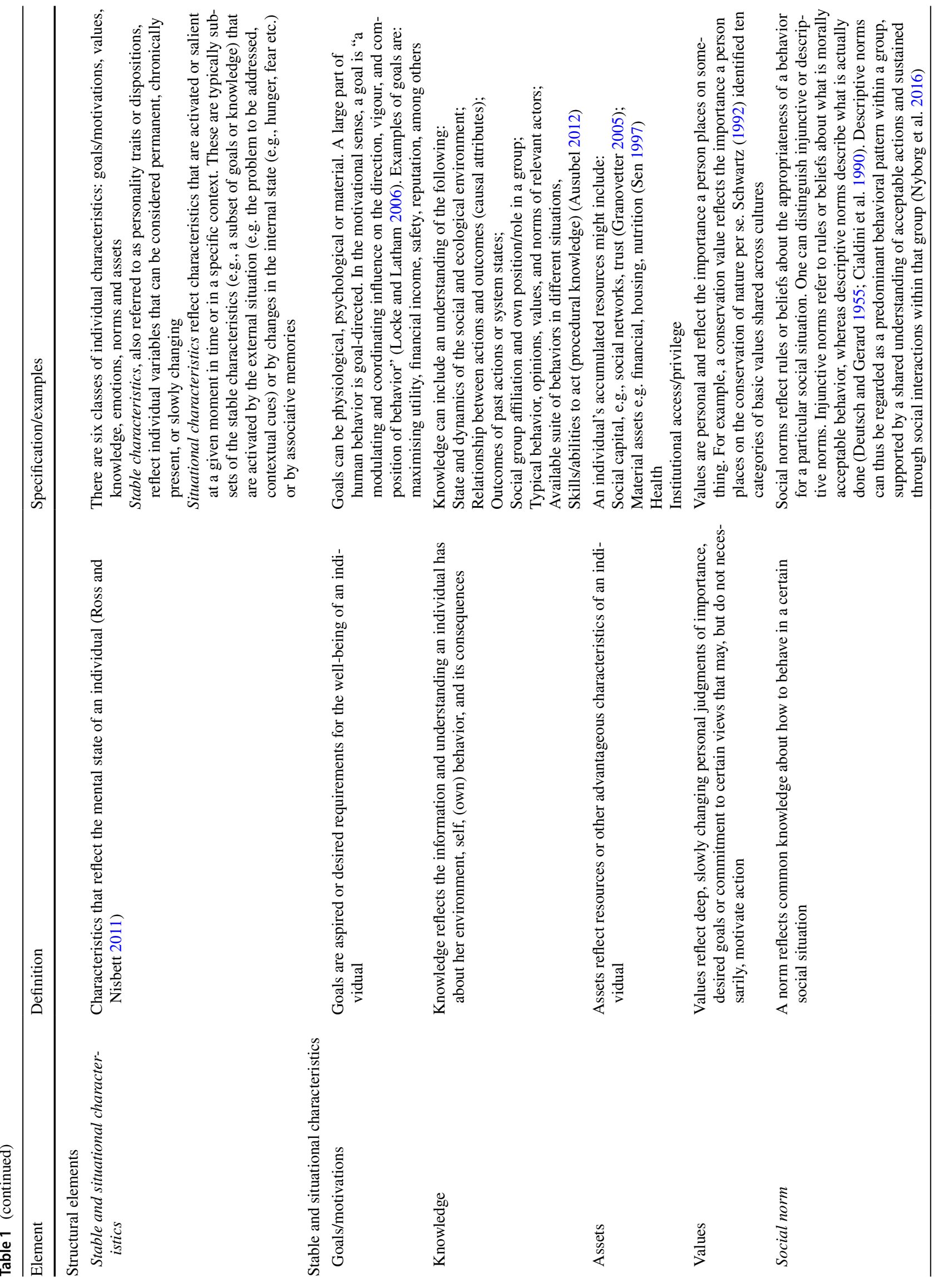




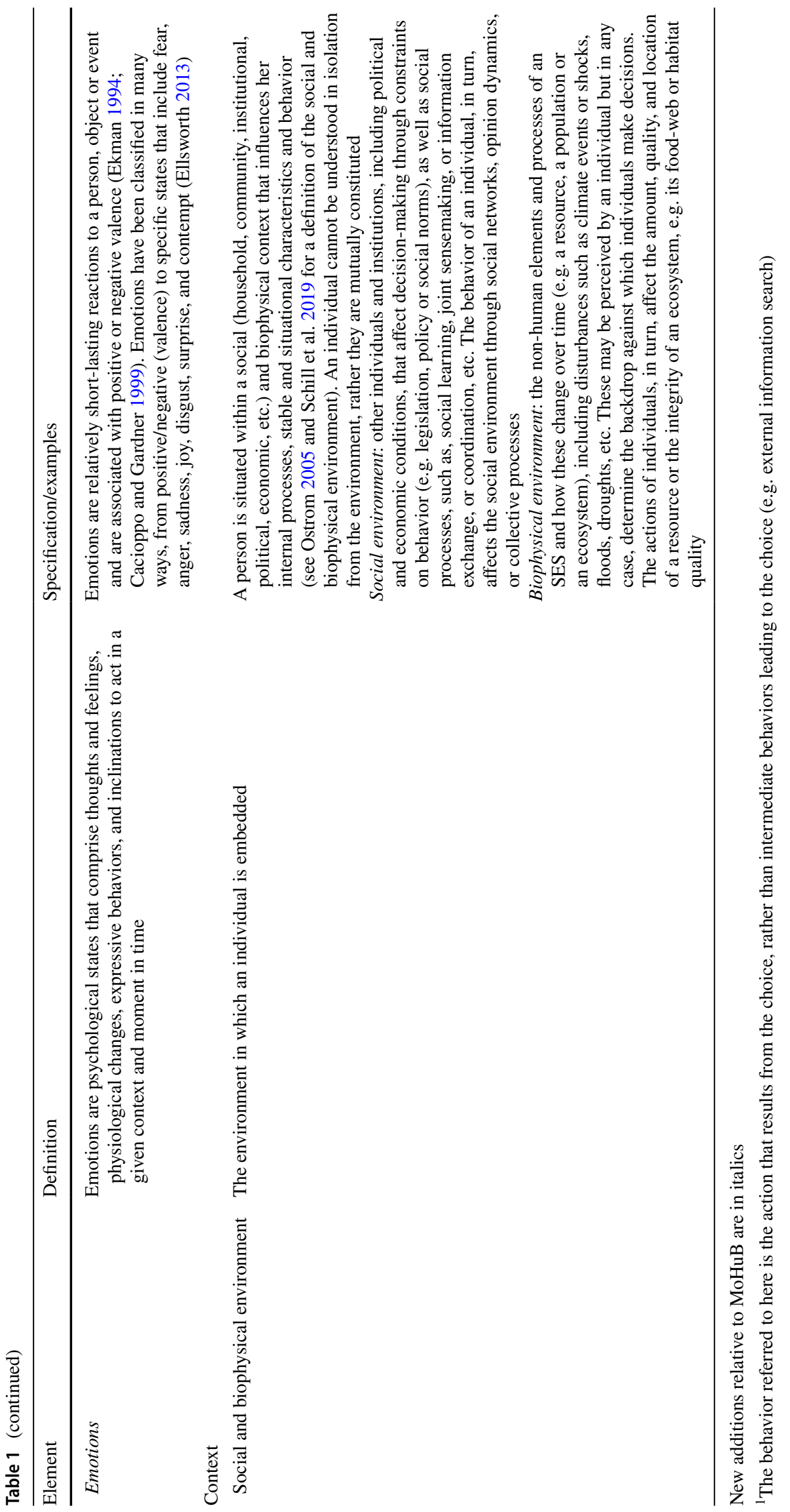




\section{Theory selection}

The selection of theories was guided by the four broad themes described in "Historical perspective: human cognition and behavior research," as well as common or puzzling behavioral patterns in SES research (described in the "Introduction," and in SM-A). The selection includes theories from behavioral economics, sociology, computer science, and human geography, as well theories that are present in more than one discipline (e.g. prospect theory, social norms, discounting). For each broad theme identified in "Historical perspective: human cognition and behavior research," we used our expertise in the behavioral sciences and SES to select a small number of well-known and highly-cited theories, prioritizing those suited to describing the individual behaviors commonly observed in empirical studies of SES. Our set of theories ranges from very specific (e.g., hyperbolic discounting, sunk cost accounting) to broader areas of research (e.g., selective attention, social identity theory) that represent collections of theories or meta-groupings. This list represents our particular expertise and is not intended to be comprehensive but rather to create useful points of entry into a daunting literature, as well as scaffolding for future efforts. We thus consider this paper to be a "living" organism, which will need to be regularly updated and refined. To this end, we have initiated a crowdsourcing effort to expand the breadth of the theories through a mass email solicitation (see SM-D for an initial list).

\section{Theory mapping}

We mapped our selection of theories onto the HuB-CC framework by indicating which of the framework's elements and processes they implicate (initial theory map in supplementary materials SM-B1, which includes the full list of theories and references). Our mapping highlights those elements and processes that are central to each theory with an ' $\mathrm{x}$ '- and involved independent mapping followed by discussion until a consensus was achieved. This exercise allows for a heuristic comparison across theories to identify those that may have similar underlying processes, as well as those that may offer complementary views of human perception and choice. In this way, the framework, which is situated between psychology and SES research, can serve as an organizing principle for a vast and varied body of crossdisciplinary knowledge on human decision-making.

To test and validate the level of expert agreement with our mapping of theories onto the key elements and processes of the framework, we issued a call through the listservs of three major US university's psychology departments in which we asked faculty and postdocs to independently map the theory selection onto the framework. These expert raters were allowed to allocate up to 3 stars per cell, indicating their level of confidence in the mapping, and were given instructions to select only those cells they considered to be central to each theory (i.e., encouraging parsimony). They were also asked to skip any theories they had limited familiarity with. Table SM-B2 provides a summary of the results of the 12 independent expert ratings. The results of our crowdsourcing exercise indicate a strong level of agreement with our initial mapping. The correlation between the independent expert votes and our own ratings (coded as a "1" when we rated a cell or " 0 " otherwise) was a highly significant +0.65 . (This correlation would be even higher if we had assigned confidence ratings to our own mapping.)

\section{HuB-CC framework and theory selection}

\section{A process-based framework for behavior in SES}

HuB-CC describes the processes and characteristics known to underlie different aspects of individual perceptions, judgments and action (Fig. 1, left). These cognitive processes are embedded in, and indeed co-constituted with, a broader social and biophysical environment (Fig. 1, right). In this framework, an actor directly interacts with human and nonhuman elements of the environment through permeable processes like perception, external information search, and behavior. Additionally, other processes and elements may be shaped by past and present environmental cues and demands through learning and updating, attention and memory. An actor is embedded and inseparable from a network of other social and ecological actors, including the family and community but also resource stocks. They are situated in a biophysical and social environment, depicted in the framework by the color gradient.

The HuB-CC is a framework, not a model, i.e., it provides concepts that are useful for describing or explaining human behavior, but does not postulate causal relationships between the elements, nor does it claim that all elements need to be present at the same time. HuB-CC is thus not an integrated theory, nor an integrated model, but it may help to identify and provide elements that are useful for constructing such a model. The elements and processes depicted in the framework are defined in Table 1, which also provides examples and canonical references.

HuB-CC differs from the original MoHuB framework in the following key ways:

- Individuals act based on stable latent characteristics and a subset of context-specific situational ones. Current states are activated by internal and external factors, thus accounting for the influence of social and biophysical context. Thus, a situated individual is in a continuous cycle of being affected by and affecting the context, and 
behavior is likely to vary across contexts, time, and individuals. This addition captures cognition in context.

- The addition of emotions and emotional states to the set of stable and situational characteristics. Emotions have rarely been considered as integral to SES research, though there is a large body of literature showing their tremendous influence in other domains. This addition reflects the multiplicity of goals and processes.

- The specification of four additional processes, namely 'Memory Search,' which links the stable and situational characteristics; 'Attention,' is a process that influences how salient characteristics influence perception and that captures cognitive and processing constraints; 'External Information Search', which links an individual to her environment through active information search; and 'Updating and Learning', which captures the process by which individuals learn the changing contingencies of dynamic environments.

\section{Mapping of theories onto the framework}

Guided by the broad themes described in "Historical perspective: human cognition and behavior research," as well as common or puzzling behavioral patterns in SES research (described in the introduction, and in SM-A), we selected 31 theories that touch on cognitive and emotional constraints, multiplicity of goals and processes, preferences and decision dynamics and cognition in a broader context. We mapped these onto the elements of the HuB-CC framework, as described in "Methods." This allows for a quick assessment of the key cognitive processes and elements that a given theory or group of theories addresses and facilitates comparison among theories. Short descriptions of each theory can be found in the glossary in SM-B2. Here, we will discuss how context is incorporated in different theories since this is especially central to cognition and behavior in SES, and is one of the primary ways in which our framework creates a cross-disciplinary bridge.

Theories within a given grouping tend to map onto similar elements of the framework, e.g. theories that focus on "constraints" often enlist attention, while those grouped under "context" and "dynamics" depend on situational characteristics. All theories grouped under "context" by design highlight the social and biophysical environment but, perhaps less obviously, theories related to "dynamics" and "multiplicity" also include the social and biophysical environment.

Theories that address context-dependence and situational factors in decision making and perception are particularly important for understanding the co-constitution of behavior and context in SES research (Schill et al. 2019). In many of the selected theories, decisions are mutually determined by the interaction between an individual and the context and so can vary depending on time, space, and the background against which the decision is made. Several theories incorporate a notion of context through situational characteristics; what this entails, however, varies substantially across theories, from the explicit consideration of the environment to the simpler conditioning of actions and perceptions on contextual cues. For example, in theories of selective attention, habitual behavior, or decision modes, the external environment is a cue that focuses limited attentional resources or triggers certain prepotent responses or styles of responding. Similarly, affordance theory explains how physical elements of the environment shape behavior by influencing perception and associations. In embodied cognition, in contrast, the body's sensorimotor capacities (in addition to the brain), the external physical and social environment, and assumptions about the world play a more active role in the coproduction of cognition. These theories emphasize that cognition is conditioned by having a body with a unique sensorimotor profile (enaction) and that these capacities are themselves embedded in a biophysical, cultural, and social context (situatedness).

Finally, social(-ecological) network theories consider the social(-ecological) embeddedness of actors and focus on the role of the network structure in shaping individual responses, including roles, obligations, and expectations (Kadushin 2012; Bodin et al. 2019). These relations are represented by the nodes and connections on the right side of Fig. 1. For example, social networks, a form of social capital, impact economic outcomes by facilitating access to jobs and opportunities (Granovetter 2005). A person's position in a network is important for behavioral interventions aimed at altering social norms or cultures. For example, changes in the behaviors or values of more centrally positioned nodes or "popular" individuals may be more efficacious for promoting widespread behavioral change (e.g. to reduce bullying in schools; Paluck et al. 2016).

\section{Using the framework and theory map}

Our framework and theory map can be used to connect SES researchers with social and behavioral science research in various ways (Fig. 2). First, they offer an accessible way into the behavioral and social sciences, and relevant terminology, for SES researchers unfamiliar with this terrain. Both the framework of embedded cognition, with its description of key processes and elements underpinning perception and decision-making, as well as the theory selection and glossary, point to canonical texts and more recent research. Second, starting from an identified pattern, problem or 


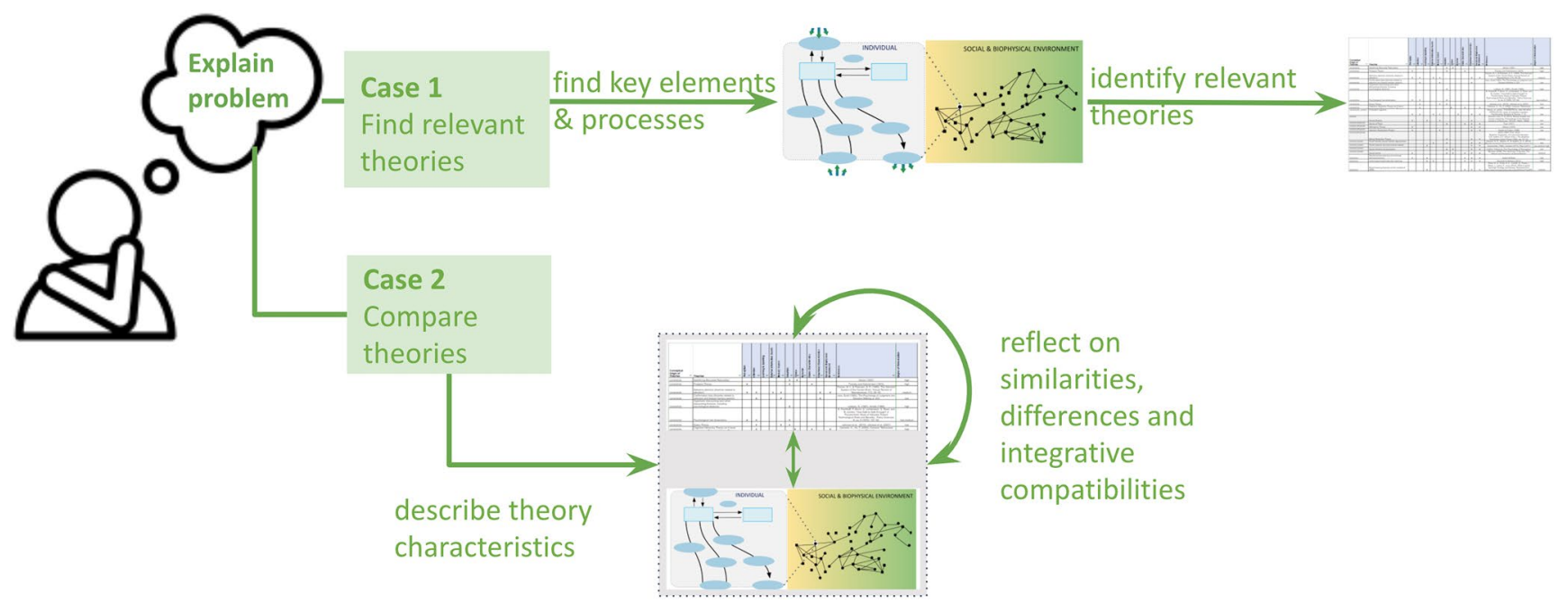

Fig. 2 Use-cases for framework and theory map. Here, we illustrate two potential uses of the theory map and framework. In case 1, a researcher starts from a puzzle or an observation for which critical elements of the decision process are clear but the theoretical explanation that accounts for the behavior is not. This researcher would turn to the framework to identify the processes and look at the theory map to identify potentially relevant theories. In case 2 , the researcher

observation, (1) the processes and elements of the framework can point to the relevant theories through the theory map (Case 1), or (2) the theory map and framework can allow a researcher to compare and contrast candidate theories in terms of their impacts on decision making (Case 2). Both pathways are relevant for empirical, theoretical, and modeling approaches to SES research.

\section{Use case 1: identifying candidate theories}

The HuB-CC framework in Fig. 1 can be used as a walkthrough guide for SES researchers to specify those processes and elements of decisions that appear most relevant for a particular context. Once potentially relevant decision elements or processes are identified, the SES researcher can search for corresponding theories by using the mapping from framework element to theories. The paragraph-long description of the identified theories in the glossary provides information about the potential relevance of each theory for explaining the behavior at hand. For theories deemed relevant, the SES researcher can then go to the reference, which in most instances also provides a review of the more general body of related theories. While this is not a guaranteed way to find the most recent and/or most relevant theory or theories to explain a puzzling pattern of behavior, it is an entry point that can guide SES researchers into at least the vicinity of relevant behavioral theories in a fairly efficient and less intimidating way. starts instead from candidate theories to explain a phenomenon or observation. Here, the researcher would use the theory map to identify the relevant framework processes for the candidate theories to shed light on how the theories differ or relate in terms of their underlying decision making process, which might be useful for subsequent modeling efforts

For example, many social and ecological dilemmas require individuals to decide how much of a shared resource to harvest (common pool resource problems; e.g. fishing), which affects how much is left for others and whether the resource stock can regenerate. In these sorts of problems, individuals fare better if they cooperate and limit their harvest. However, they also have a personal incentive to overharvest (Gardner et al. 1990). Often these situations are complicated by uncertainty about the state of the resource and possible social-ecological tipping points. While uncertainty about ecological thresholds has been shown to erode cooperation and the possibility for collective action, even in circumstances where communication is possible (Barrett and Dannenberg 2014), a recent field study found that Colombian fishers playing a common pool resource game actually cooperated more under conditions of uncertainty (Rocha et al. 2019). The participants in this game differ from the standard experimental subjects: they come from an established community and their livelihoods depend on natural resources. Developing an explanation for why uncertainty promotes cooperation in one social context but erodes it in another can be facilitated by consulting the framework.

Perception is an important element here since cooperation depends on whether the properties of the environment are known and certain, known and risky or unknown. The social and biophysical environment is also central since the problem involves group choices that impact the state of the natural resource. Individuals must assess whether the group is composed of unpredictable and presumably uncooperative 
strangers or known partners with whom they have longterm relationships. Valuation is another critical element that allows individuals to decide on the likely consequences of cooperating (and building good will in the community and longer-term survival of the public good) or of fishing at capacity (to maximize immediate income). Cooperation under the same degree of uncertainty about tipping-points in the resource can lead to different decisions depending on whether the social context involves strangers or an individual's community. In particular, uncertainty about the threshold may induce uncertainty about whether others are cooperating, and the assumptions will likely differ between the two circumstances. None of the other process elements of Fig. 1 seem particularly relevant when considered for this task: Attention, Learning, External Information would presumably not differ in important ways when this decision is made in the context of strangers or community members, though of course social learning and history of cooperation, which might be recalled through memory search, could have impacted the social norms, perceived response options, and other situational and stable characteristics. Choice and Behavior (which of course do differ) follow naturally from the difference in Valuation and thus are not relevant.

When we highlight the three-column elements of 'Perception', 'Valuation', and 'Social and Biophysical Environment' in Table 2, we see that 'Psychological Risk Dimensions', 'Social Norms', and 'Trust and Reciprocity' have an ' $x$ ' for all three framework elements. Further perusal of the paragraph-long theory summaries in the Supplementary Material or the papers referenced for each one would indicate that all three are likely to contribute to the observed behavioral pattern: familiar social environments may reduce feelings of risk. Additionally, operating in a community where cooperation may be an implicit social norm, where there is a history of experiences that may have established high levels of trust, and where maintaining a positive reputation may reap future benefits makes cooperation a more highly valued option, even with unknown underlying risks. Using these theories and the related decision processes to illuminate the results of the experiment, SES researchers can generate hypotheses for additional studies or use the candidate theories and processes to develop formal models of decisionmaking in contexts with unknown social-ecological tipping points.

\section{Use case 2: comparing and integrating candidate theories}

The framework and theory map can also be used to help an SES researcher compare and possibly integrate several candidate theories to explain an observed phenomenon. For example, fishers sell their products at a lower price to certain buyers to maintain social relations. A knowledgeable
SES researcher may start from two candidate theories: social identity theory (Tajfel and Turner 1986; Reicher et al. 2010) and conditional cooperation and reciprocity (Berg et al. 1995; Gächter 2006). These are both accounts of behavior that are dependent on social relations and group membership.

Social identity theory differentiates among actors as belonging to "us" or "them" groups, placing perceived similarities and differences with others at the heart of explanations about group dynamics (Tajfel and Turner 1986; Reicher et al. 2010). This approach accounts for price differentiation with the existence of multiple social identities. Depending on which identity is salient in a given context and the prominence of the group with which an individual identifies, the fisher may price-discriminate depending on the group membership of the buyer. Specifically, this application of the theory would predict lower prices for ingroup members and higher prices for outgroup members. On the other hand, conditional cooperation (Berg et al. 1995; Gächter 2006) describes a decision strategy where one's willingness to cooperate depends on whether the person one is dealing with previously cooperated or not. The cheaper price may thus reflect a positive feedback mechanism in response to a previous favor.

For SES researchers who have these two theories in mind as potential alternative explanations, the Theory Map and Framework can be used to better understand how the theories relate and differ in terms of their underlying processes. For example, Social Identity Theory involves 'External Information Search,' which allows the decision-maker to identify the group membership of others and to assess the position of this group in a given social context. "Valuation' accounts for how this information is incorporated into estimations about the appropriate price for a given buyer. 'Situational Characteristics' reflect the salience of a certain identity and associated social norms. Conditional Cooperation Theory also implicates 'Situational Characteristics' and the 'Social and Biophysical Environment,' suggesting that the two theories at a process level share commonalities, but it also implicates 'Choice,' which highlights the tit-for-tat choice strategy rather than a person-specific valuation. These differences can be used to compare and contrast the two theories, to examine whether they describe common or distinct processes, and to develop models which can be used to capture the observed price differentiation. The combination of data and model may start to disentangle which theory and processes are most relevant here, or point to the possibility that they should be integrated. Furthermore, the framework serves as an organizational device to facilitate interdisciplinary conversations about the role of these two theories in the embedded decision-making and cognition that is central to SES approaches. 


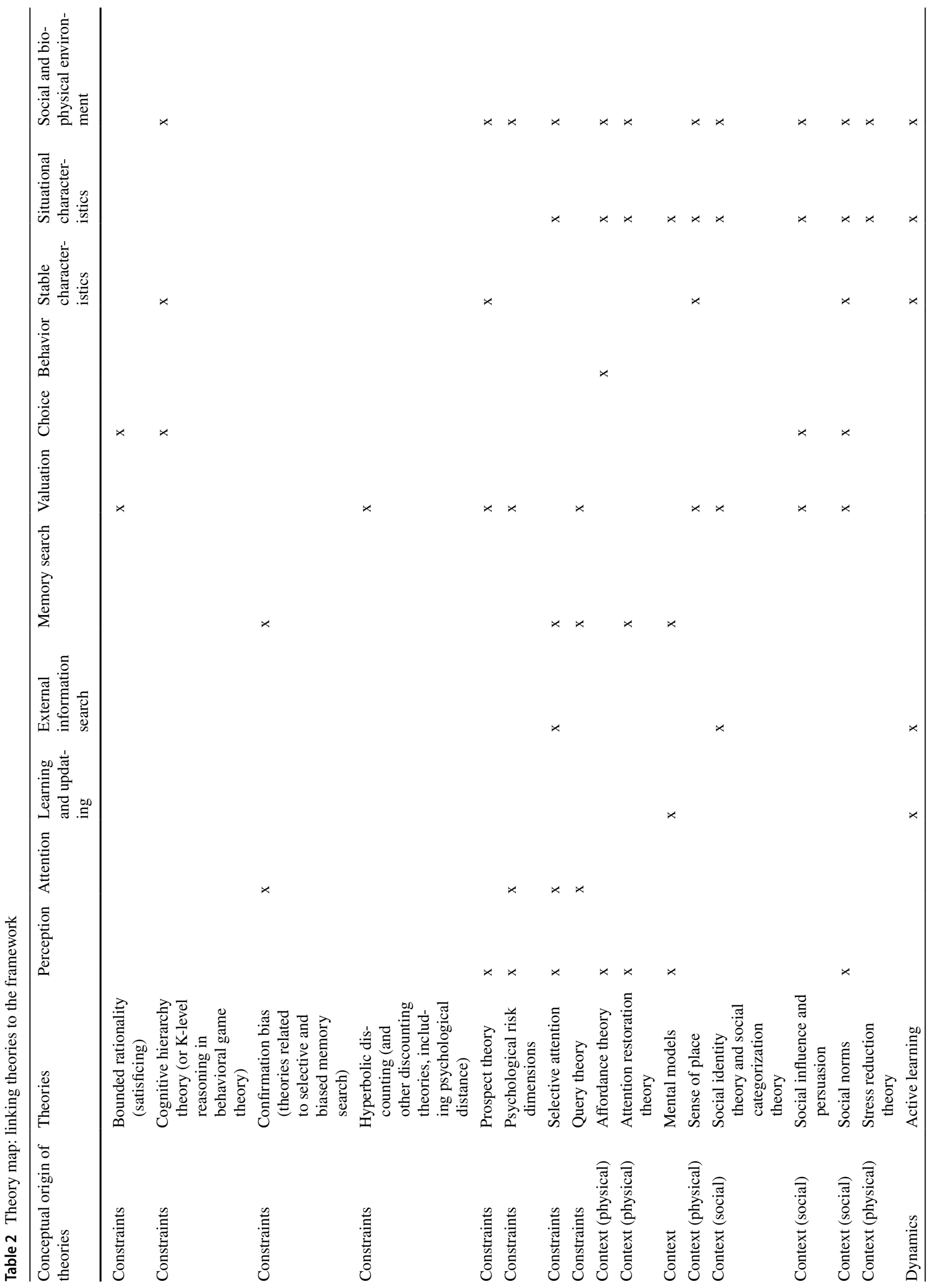




$$
[
$$




\section{Discussion}

A deeper understanding of human decisions in socialecological systems and the design and implementation of effective policy interventions require accounting for both the diversity of actors and their sensitivity to situational or contextual factors when making resource use and management decisions. In this paper, we introduce two tools to facilitate the inclusion of social science knowledge into the study of human behavior in SES: (1) a framework (HuB-CC) of embedded cognition that organizes the elements and processes underlying perception and decision-making in SES and natural resource use contexts (2) an initial selection and mapping of theories from the behavioral and social sciences that can advance the accessibility, understanding, and incorporation of diverse human behavior in studies of resource use and management. Both framework and the set of theories are intended as a foundation for future cross-disciplinary collaborations-below we indicate some promising future avenues for this research.

HuB-CC starts from the premise that individuals are complex cognitive beings embedded in social, institutional, and ecological environments. Our initial selection of theories thus aimed to include literature that accounts for the relational dimension between individuals and their surroundings and the diversity of factors influencing decision-making. A key ingredient of $\mathrm{HuB}-\mathrm{CC}$ is the distinction between an individual's stable (permanent or slowly evolving) characteristics and the subset of situational (temporarily activated, quickly evolving) characteristics, which captures the situatedness of behavior. This is particularly relevant for understanding or modelling how resource users' behavior is influenced by changes in the biophysical environment or social influences and follows a large body of literature on the temporary priming of values and goals (e.g. Bargh et al. 2001). We also distinguish between choice and behavior to account for theories that make this distinction by considering agency and behavioral intentions as distinct from choice and valuation (e.g. Theory of Planned Behaviour). These process-level details support a growing interest in developing more nuanced theories and models of social-ecologically embedded human behavior in SES research.

The HuB-CC structure supports the selection, organization, and comparison of theories from the behavioral and social sciences. We identified and mapped 31 theories of situated decision-making, which we believe have the potential to explain observed behavioral patterns in SES or natural resource use contexts, and for predicting the dynamics by which societal adaptations or transitions will unfold. In addition to policy implications, described in more detail below, we hope this organizational device offers a starting point for a community effort to collect, map, and evaluate theories (see "Future directions" below).

\section{Policy implications}

Our framework intends to help move policy design and implementation towards more nuanced and realistic assumptions about human decision-making, with the goal of making natural resource management policies more efficient and effective. Examination of the theories we selected, described, and put to use in different examples throughout the paper can increase awareness of a broader range of motivations and processes driving resource use decisions, and with this more avenues for policy to affect behavior. The framework and theories can help answer questions about policy implementation; for example, deciding whether a subsidy for propane should be provided as a cost reduction at time of purchase or as a tax refund at a later point in time. While this difference in timing should not matter under conventional economic analysis, the mental accounting described by prospect theory suggests that implementation of the cost reduction at time of purchase will significantly enhance the uptake of the better fuel option.

To take another example, SES research has also found that limiting total harvests on a yearly basis leads fisher to catch as much as they can in as little time as possible, driving them to overinvest in powerful boats and giant nets, and to take dangerous risks ("run for fish"; McDermott et al. 2019). Research in behavioral economics and ecology suggests that many animals, including humans, are hyperbolic discounters-we tend to discount the future steeply vis a vis the present (Ainslie and Haslam 1992; Laibson 1997). Accounting for hyperbolic discounting and related theories may help policymakers and researchers anticipate that fishers may favor immediate gains, even when they incur longer term financial losses. This knowledge, imported from other domains, suggests that policy mechanisms that account for these temporal dynamics, by introducing commitment devices and carefully considering the time frame over which quotas are defined, may be especially important in these contexts. In this case, the inclusion of a single parameter ("present bias") to the discount function could go quite some way towards accounting for observed behavior (Laibson 1997). Other cases might require more extensive reconceptualizations of behavior, and may generate novel explanations or models. While we have focused here on natural resource management, we expect that many of the benefits of more nuanced considerations of behavior, and its diverse drivers, will generalize to other policy domains. 


\section{Human behavior in SES: contributions to an emerging research frontier}

Our focus on the complexity of human behavior and its embeddedness in social and biophysical contexts places our framework alongside a recently emerging research frontier of human behavior in complex, adaptive SES (Schill et al. 2019). This research focuses on how biophysical and social contexts shape and are in turn shaped by local actions and interactions. One strand of this work has focused on deviations from standard rational actor models and largely draws on the group of theories we have identified as 'focused on constraints.' Examples of this approach include descriptions of behavior that focus on bounded rationality and satisficing, imitation and mimicry, or social norms as shortcuts or heuristics (Libre et al. 2015; e.g., Dressler et al. 2018; Wijermans et al. 2020). These are largely quantitative, experimental or model-based SES studies that use, for instance, prospect theory (e.g. Bert et al. 2011), the Theory of Planned Behavior (e.g., Beckage et al. 2018; Muelder and Filatova 2018; Schwarz and Ernst 2009), or behavioral game theoretic approaches (Janssen et al. 2010; Lindahl et al. 2016). Another similar strand of research focuses on the role of cognitive biases in complex cooperative dilemmas, such as adaptive environmental governance (DeCaro et al. 2017). This work emphasizes the implications of biases in group settings and for sustainability issues (Engler et al. 2017). Yet another strand of work has focused on incorporating research from cognitive science into complexity-based descriptions of individual and collective decision making in SES (Beratan 2007; Levine et al. 2015). Epstein (2014) offers a general framework for agent-based modelling (Agent Zero) based on evidence from psychology and neuroscience, which includes social, emotional, and rational processing components. Finally, theories such as affordance theory, sense of place, and some aspects of embodied cognition; (Stedman 2002; Masterson et al. 2017; Raymond et al. 2018; Kaaronen and Strelkovskii 2020) have been applied within sustainability science to facilitate the study of human behavior as embedded within its biophysical surroundings.

Our framework and taxonomy build on and complement these nascent efforts but go further by (a) engaging with theories that extend beyond the ones previously considered, (b) developing a process-based account of how the context impacts cognition and behavior, and how behavior, in turn, impacts the context, which helps to bridge studies of human decision-making and SES approaches, and (c) integrating theories into this framework to understand which ones incorporate a role for the social and physical contexts, and how this influence manifests.

\section{Future directions}

The HuB-CC framework and our selection and mapping of theories are a step towards incorporating cognitive and social science knowledge into empirical and model-based research in sustainability science. Both the framework and the set of selected theories are intended as the foundation for a dynamic and living resource to stimulate further community efforts. We invite scholars to add theories and map them onto the framework, and to suggest extensions to the framework, with the aim of increasing the diversity of theories, contexts, perspectives, and populations. It was beyond the scope of this paper, for instance, to include theories that explicitly consider politics or culture. These theories, however, are relevant for understanding the role of the socialecological context. We can see these theories emerging in our initial efforts to crowdsource relevant theories (SM-D) and hope to incorporate these in more detail in future work. To this end, we created a website to facilitate these community efforts.

One drawback of our current selection of theories, which is nonetheless symptomatic of the current state of much academic research, is that many, if not all, of the theories we identified were developed in studies conducted by, in, or with Western, educated, industrialized, rich and democratic (WEIRD) populations. This lack of diversity may limit their applicability to non-WEIRD environments, which are often the very environments where much SES research is set (Henrich et al. 2010). Several studies on preferences have found substantial heterogeneity in discounting, risk, and prosociality both within and across countries, which is predicted in part by biogeographic and cultural variables (Falk et al. 2018; Tiokhin et al. 2019). While a thorough analysis of the cross-cultural relevance of the theories and processes was beyond the scope of this paper, we believe that testing their generalizability and expanding this list to include emerging theories and perspectives from the Global South and non-WEIRD populations is a priority for subsequent work. We hope that the foundation we have built provides the initial footing for subsequent efforts to extend this "living" document. While theories may need to be adapted or dropped altogether, we believe the framework offers a flexible platform with its focus on basic cognitive functions, their embeddedness in dynamic environments, and the heterogeneity this conception invites. However, even here there are likely to be important additions that we have overlooked. In our ongoing outreach to crowdsource theories and validate our mapping, we will continue our efforts to engage academics and practitioners from the Global South and those who work with different types of methodologies and communities.

In addition, we envision several next steps regarding further development and application of our work. First, many of 
the highlighted theories focus on particular aspects of decision making. It might thus be fruitful to integrate across theories to explain broader patterns of behavior and to inform data analysis, models or policy. Given the context-dependence of human decision-making, we do not suggest a single unified theory, but rather the identification of a set of theories applicable to different contexts. Second, many theories are conceptual and have not been mathematically formalized. To be applicable for modelling and experimental work, theories will need to be operationalized, e.g. in an agentbased model. Ultimately, a "pick and play" actor model that can be adapted for various contexts to test whether it matches behavioral observations would be a formidable tool to understand and anticipate behavior, evaluate policy, and develop novel governance approaches. The framework and theory mapping may offer an especially promising path forward for these efforts by highlighting plausible underlying mechanisms or process-based accounts. The framework and theory selection should be extended to incorporate exogenous environmental or institutional changes or disturbances, in addition to the endogenous change processes we have identified, so that they can be used to analyze expected responses to new policies or governance approaches. Third, we have so far focused on individual decision-making. Given that sustainability issues are often collective action problems, a logical next step is to expand the theory selection and framework to include theories of collective and group decision making. Fourth, additional work is needed to systematically survey and classify empirically observed behavioral patterns and match them to theories to anticipate more nuanced policy responses and design. Finally, while there is increasing attention in SES research to the relations (social and social-ecological) that shape SES, many theories do not specify the details of these relations. They refer to "context" in more general terms or focus on aspects of the context that have been internalized by the agent, e.g. a norm or a social identity. More attention is needed to the influence of different groups, relations within and between groups, and the biophysical environment on behavior, and, in turn, of behavior and interactions between actors on the production of context.

\section{Conclusions}

In this paper, we present a framework that facilitates the selection, comparison, and integration of theories from the social and cognitive sciences with the joint aims of improving our understanding of human behavior in socialecological contexts and addressing behavioral challenges to sustainability. Using the framework, we organize theories by process-level features of decision-making to assist with the integration of cognitive and social science insights into sustainability science and governance. We envision the HuB-CC framework to be a work in progress, evolving to accommodate additional characteristics, processes, and theories and more nuanced approaches to SES research, and hopefully inspiring the development of new theories in the process.

Supplementary Information The online version contains supplementary material available at https://doi.org/10.1007/s11625-021-00989-w.

Acknowledgements We would like to thank the Princeton-SRC collaboration for supporting an in-person meeting that facilitated cross-institution collaboration on this project. MS acknowledges funding from the European Research Council (ERC) under the European Union's Horizon 2020 research. MS and NW acknowledge funding from the innovation programme (Grant Agreement No 682472-MUSES). NW also acknowledges funding from the Swedish Research Council Formas (Grant No. 2018-00401). SMC would like to thank the Science, Technology and Environment Program (STEP) at the School of Public and International Affairs at Princeton University for salary support. We are grateful to Kriszti Jónás and Robert Britt for a friendly review of the paper and editorial assistance.

Author contributions All authors designed the framework, selected and mapped the theories into a taxonomy, wrote the manuscript, and participated in regular online discussions from 2017 to 2020 . All authors contributed equally to the content of the paper and NW organized the process of this intercontinental interdisciplinary collaboration.

Funding Open access funding provided by Stockholm University.

\section{Declarations}

Conflict of interest The authors declare no competing interests.

Open Access This article is licensed under a Creative Commons Attribution 4.0 International License, which permits use, sharing, adaptation, distribution and reproduction in any medium or format, as long as you give appropriate credit to the original author(s) and the source, provide a link to the Creative Commons licence, and indicate if changes were made. The images or other third party material in this article are included in the article's Creative Commons licence, unless indicated otherwise in a credit line to the material. If material is not included in the article's Creative Commons licence and your intended use is not permitted by statutory regulation or exceeds the permitted use, you will need to obtain permission directly from the copyright holder. To view a copy of this licence, visit http://creativecommons.org/licenses/by/4.0/.

\section{References}

Ainslie G, Haslam N (1992) Hyperbolic discounting. Choice over time. Russell Sage Foundation, New York, pp 57-92

Atkinson RC, Shiffrin RM (1968) Human memory: a proposed system and its control processes. In: Spence KW, Spence JT (eds) The psychology of learning and motivation. Academic Press, New York, pp 89-195

Ausubel DP (2012) The acquisition and retention of knowledge: a cognitive view. Springer Science \& Business Media 
Bansal M, Saini RP, Khatod DK (2013) Development of cooking sector in rural areas in India-a review. Renew Sustain Energy Rev 17:44-53. https://doi.org/10.1016/j.rser.2012.09.014

Bargh JA, Lee-Chai A, Barndollar K, Gollwitzer PM, Trotschel R (2001) The automated will: nonconscious activation and pursuit of behavioral goals. J Pers Soc Psychol 81:6

Barrett S, Dannenberg A (2014) Sensitivity of collective action to uncertainty about climate tipping points. Nat Clim Change 4:36-39. https://doi.org/10.1038/nclimate2059

Basurto X, Bennett A, Weaver AH et al (2013) Cooperative and noncooperative strategies for small-scale fisheries' self-governance in the globalization era: implications for conservation. Ecol Soc $18: 38$

Beckage B, Gross LJ, Lacasse K et al (2018) Linking models of human behavior and climate alters projected climate change. Nat Clim Change 8:79-84

Beratan K (2007) A cognition-based view of decision processes in complex social-ecological systems. Ecol Soc. https://doi.org/10. 5751/ES-02103-120127

Berg J, Dickhaut J, McCabe K (1995) Trust, reciprocity, and social history. Games Econ Behav 10:122-142. https://doi.org/10.1006/ game.1995.1027

Bert FE, Podestá GP, Rovere SL et al (2011) An agent based model to simulate structural and land use changes in agricultural systems of the Argentine pampas. Ecol Model 222:3486-3499. https:// doi.org/10.1016/j.ecolmodel.2011.08.007

Bettman JR (1979) Information processing theory of consumer choice. Addison-Wesley Pub. Co.

Bicchieri C (2006) The grammar of society: the nature and dynamics of social norms. Cambridge University Press

Bodin Ö, Alexander SM, Baggio J et al (2019) Improving network approaches to the study of complex social-ecological interdependencies. Nat Sustain 2:551-559. https://doi.org/10.1038/ s41893-019-0308-0

Cacioppo JT, Gardner WL (1999) Emotion. Annu Rev Psychol 50:191214. https://doi.org/10.1146/annurev.psych.50.1.191

Camerer CF (1998) Prospect theory in the wild: evidence from the field. California Institute of Technology, Pasadena

Cialdini R, Reno R, Kallgren C (1990) A focus theory of normative conduct: recycling the concept of norms to reduce littering in public places. J Pers Soc Psychol 58:1015-1026. https://doi.org/ 10.1037/0022-3514.58.6.1015

Constantino S, Daw ND (2015) Learning the opportunity cost of time in a patch-foraging task. Cogn Affect Behav Neurosci 15:837853. https://doi.org/10.3758/s13415-015-0350-y

Craik FIM, Lockhart RS (1972) Levels of processing: a framework for memory research. J Verbal Learn Verbal Behav 11:671-684. https://doi.org/10.1016/S0022-5371(72)80001-X

Crona BI, Daw TM, Swartz W et al (2015) Masked, diluted and drowned out: how global seafood trade weakens signals from marine ecosystems. Fish Fish. https://doi.org/10.1111/faf.12109

Dayan P, Daw ND (2008) Decision theory, reinforcement learning, and the brain. Cogn Affect Behav Neurosci 8:429-453. https://doi. org/10.3758/CABN.8.4.429

DeCaro D, Chaffin B, Schlager E et al (2017) Legal and institutional foundations of adaptive environmental governance. Ecol Soc. https://doi.org/10.5751/ES-09036-220132

Deutsch M, Gerard HB (1955) A study of normative and informational social influences upon individual judgement. J Abnorm Psychol 51(3):629-636

Dressler G, Groeneveld J, Buchmann CM et al (2018) Implications of behavioral change for the resilience of pastoral systems-lessons from an agent-based model. Ecol Complex 40:100710

Ekman P (1994) The nature of emotion: fundamental questions. Oxford University Press, New York
Ellsworth PC (2013) Basic emotions and the rocks of New Hampshire. Emot Rev 6:21-26

Engler J-O, Abson DJ, von Wehrden H (2017) 'It's the psychology, stupid!' Understanding human cognition biases to inform sustainable behavior. Social Science Research Network, Rochester

Epstein JM (2014) Agent_Zero: toward neurocognitive foundations for generative social science. Princeton University Press

Falk A, Becker A, Dohmen T, Enke B, Huffman D, Sunde U (2018) Global evidence on economic preferences. Q J Econ 133(4):1645-1692

Fechner GT (1860) Elemente der psychophysik. Breitkopf u. Härtel

Fulton EA, Smith ADM, Smith DC, van Putten IE (2011) Human behavior: the key source of uncertainty in fisheries management. Fish Fish 12:2-17

Gächter S (2006) Conditional cooperation: behavioral regularities from the lab and the field and their policy implications. The University of Nottingham, Nottingham

Gardner R, Ostrom E, Walker JM (1990) The nature of common-pool resource problems. Ration Soc 2:335-358. https://doi.org/10. $1177 / 1043463190002003005$

Gibson JJ (1966) The senses considered as perceptual systems. Houghton Mifflin

Gibson JJ (1979) The ecological approach to visual perception. Houghton Mifflin

Gläscher J, Daw N, Dayan P, O’Doherty JP (2010) States versus rewards: dissociable neural prediction error signals underlying model-based and model-free reinforcement learning. Neuron 66(4):585-595

Granovetter M (1985) Economic action and social structure: the problem of embeddedness. Am J Sociol 91:481-510. https://doi.org/ $10.1086 / 228311$

Granovetter M (2005) The impact of social structure on economic outcomes. J Econ Perspect 19:33-50. https://doi.org/10.1257/08953 30053147958

Groeneveld J, Müller B, Buchmann CM et al (2017) Theoretical foundations of human decision-making in agent-based land use models-a review. Environ Model Softw 87:39-48. https://doi. org/10.1016/j.envsoft.2016.10.008

Habermas J (1987) Knowledge and human interests. Polity Press, Cambridge

Hastie R, Dawes RM (2009) Rational choice in an uncertain world: the psychology of judgment and decision making. SAGE Publications

Henrich J, Heine SJ, Norenzayan A (2010) The weirdest people in the world? Behav Brain Sci 33(2-3):61-83

Hilgard ER (1987) Psychology in America: a historical survey. Harcourt Brace Jovanovich, San Diego

Hukkinen JI (2014) Model of the social-ecological system depends on model of the mind: contrasting information-processing and embodied views of cognition. Ecol Econ 99:100-109. https:// doi.org/10.1016/j.ecolecon.2014.01.017

Janssen MA, Holahan R, Lee A, Ostrom E (2010) Lab experiments for the study of social-ecological systems. Science 328:613617. https://doi.org/10.1126/science.1183532

Johnson EJ, Häubl G, Keinan A (2007) Aspects of endowment: a query theory of value construction. J Exp Psychol Learn Mem Cogn 33:461-474. https://doi.org/10.1037/0278-7393.33.3.461

Johnson EJ, Shu SB, Dellaert BGC et al (2012) Beyond nudges: tools of a choice architecture. Mark Lett 23:487-504. https://doi.org/ 10.1007/s11002-012-9186-1

Kaaronen RO (2017) Affording sustainability: adopting a theory of affordances as a guiding heuristic for environmental policy. Front Psychol. https://doi.org/10.3389/fpsyg.2017.01974

Kaaronen RO, Strelkovskii N (2020) Cultural evolution of sustainable behaviors: pro-environmental tipping points in an 
agent-based model. One Earth 2:85-97. https://doi.org/10. 1016/j.oneear.2020.01.003

Kadushin C (2012) Understanding social networks: theories, concepts, and findings. Oxford University Press, New York

Kahneman D, Tversky A (eds) (2000) Choices, values, and frames. Cambridge University Press, New York

Kahneman D (2003) A perspective on judgment and choice: mapping bounded rationality. Am Psychol 58:697-720. https://doi.org/ 10.1037/0003-066X.58.9.697

Kahneman D, Tversky A (1979) Prospect theory: an analysis of decision under risk. Econometrics 47:263-292

Kahneman D, Gilovich T, Griffin D, Press CU (2002) Heuristics and biases: the psychology of intuitive judgment. Cambridge University Press

Krosch A, Figner B, Weber EU (2012) Choice processes and their post-decisional consequences in morally conflicting decisions. Social Science Research Network, Rochester

Laibson D (1997) Golden eggs and hyperbolic discounting. Q J Econ 112:443-478. https://doi.org/10.1162/003355397555253

Levine J, Muthukrishna M, Chan KMA, Satterfield T (2015) Theories of the deep: combining salience and network analyses to produce mental model visualizations of a coastal British Columbia food web. Ecol Soc. https://doi.org/10.5751/ES-08094-200442

Libre SVD, van Voorn GAK, ten Broeke GA et al (2015) Effects of social factors on fishing effort: the case of the Philippine tuna purse seine fishery. Fish Res 172:250-260. https://doi.org/10. 1016/j.fishres.2015.07.033

Lieder F, Griffiths TL (2019) Resource-rational analysis: understanding human cognition as the optimal use of limited computational resources. Behav Brain Sci. https://doi.org/10.1017/S0140525X1 900061X

Lindahl T, Crépin A-S, Schill C (2016) Potential disasters can turn the tragedy into success. Environ Resour Econ 65:657-676. https:// doi.org/10.1007/s10640-016-0043-1

Locke EA, Latham GP (2006) New directions in goal-setting theory. Curr Dir Psychol Sci 15:265-268. https://doi.org/10.1111/j.14678721.2006.00449.x

Luce R (1959) Individual choice behavior: a theoretical analysis. John Willey and Sons Inc, New York

Luce RD (1977) The choice axiom after twenty years. J Math Psychol 15:215-233

March JG (1994) Primer on decision making: how decisions happen. Simon and Schuster

March JG (1997) Understanding how decisions happen in organizations. Organ Decis Mak 10:9-32

March JG, Olsen JP (1996) Institutional perspectives on political institutions. Governance 9:247-264. https://doi.org/10.1111/j. 1468-0491.1996.tb00242.x

Maslow AH (1943) A theory of human motivation. Psychol Rev 50:370-396. https://doi.org/10.1037/h0054346

Masterson V, Stedman R, Enqvist J et al (2017) The contribution of sense of place to social-ecological systems research: a review and research agenda. Ecol Soc. https://doi.org/10.5751/ ES-08872-220149

McDermott GR, Meng KC, McDonald GG, Costello CJ (2019) The blue paradox: preemptive overfishing in marine reserves. Proc Natl Acad Sci 116:5319-5325. https://doi.org/10.1073/pnas. 1802862115

McGinnis MD (2011) An introduction to IAD and the language of the Ostrom workshop: a simple guide to a complex framework. Policy Stud J 39:169-183. https://doi.org/10.1111/j.1541-0072. 2010.00401.x

Mellers BA, Schwartz A, Cooke ADJ (1998) Judgment and decision making. Annu Rev Psychol 49:447-477. https://doi.org/10. 1146/annurev.psych.49.1.447
Muelder H, Filatova T (2018) One theory-many formalizations: testing different code implementations of the theory of planned behavior in energy agent-based models. J Artif Soc Soc Simul 21:5

Nyborg K, Anderies JM, Dannenberg A et al (2016) Social norms as solutions. Science 354:42-43

O'Neill DL (2017) Women hunters in the octopuses' gardens. Re.Think

O'Neill ED, Asare N, Aheto D (2018) Socioeconomic dynamics of the Ghanaian tuna industry: a value-chain approach to understanding aspects of global fisheries. Afr J Mar Sci 40:303-313. https://doi.org/10.2989/1814232X.2018.1513866

Ostrom E (1990) Governing the commons. The evolution of institutions for collective action. Cambridge University Press, New York

Ostrom E (2005) Understanding institutional diversity. Princeton University Press, Princeton

Paluck EL, Shepherd H, Aronow PM (2016) Changing climates of conflict: a social network experiment in 56 schools. Proc Natl Acad Sci 113:566-571. https://doi.org/10.1073/pnas.15144 83113

Pashler HE (1998) The psychology of attention. MIT Press, Cambridge

Payne JW, Bettman JR, Coupey E, Johnson EJ (1992) A constructive process view of decision making: multiple strategies in judgment and choice. Acta Psychol (amst) 80:107-141. https://doi. org/10.1016/0001-6918(92)90043-D

Peattie K (2010) Green consumption: behavior and norms. Annu Rev Environ Resour 35:195-228. https://doi.org/10.1146/annurevenviron-032609-094328

Raymond CM, Giusti M, Barthel S (2018) An embodied perspective on the co-production of cultural ecosystem services: toward embodied ecosystems. J Environ Plan Manag 61:778-799. https://doi.org/10.1080/09640568.2017.1312300

Reeck C, Gamma K, Weber EU (2018) Feeling green: decision modes promoting environmentally-friendly consumer utility choices. In: Hackenfort M, Carabias-Hütter V, Hartmann C, Janser, M, Schwarz N, Stücheli-Herlach P (eds) BEHAVE 2018 book of abstracts-conference proceedings

Reicher SD, Spears R, Haslam SA (2010) The social identity approach in social psychology. In: Wetherell M, Mohanty CT (eds) The sage handbook of identities. Sage, United States

Rescorla RA, Wagner AR et al (1972) A theory of Pavlovian conditioning: variations in the effectiveness of reinforcement and nonreinforcement. Class Cond II Curr Res Theory 2:64-99

Reyers B, Folke C, Moore M-L et al (2018) social-ecological systems insights for navigating the dynamics of the anthropocene. Annu Rev Environ Resour 43:267-289. https://doi.org/10.1146/annur ev-environ-110615-085349

Rocha JC, Schill C, Diaz LMS et al (2019) Cooperation in the face of thresholds, risk, and uncertainty. Social Science Research Network, Rochester

Ross L, Nisbett RE (2011) The person and the situation. Pinter \& Martin Publishers

Schill C, Anderies JM, Lindahl T et al (2019) A more dynamic understanding of human behavior for the Anthropocene. Nat Sustain 2:1-8

Schlüter M, Baeza A, Dressler G et al (2017) A framework for mapping and comparing behavioral theories in models of socialecological systems. Ecol Econ 131:21-35

Schwartz SH (1992) Universals in the content and structure of values: theoretical advances and empirical tests in 20 countries. Adv Exp Soc Psychol 25:1-65

Schwarz N, Ernst A (2009) Agent-based modeling of the diffusion of environmental innovations-an empirical approach. Technol Forecast Soc Change 76:497-511 
Sen A (1997) Resources, values, and development. Harvard University Press

Simon HA (1957) Models of man; social and rational. Wiley, Oxford

Sims CA (2006) Rational inattention: beyond the linear-quadratic case. Am Econ Rev 96:158-163. https://doi.org/10.1257/00028 2806777212431

Stedman RC (2002) Toward a social psychology of place: predicting behavior from place-based cognitions, attitude, and identity. Environ Behav 34:561-581. https://doi.org/10.1177/00139 16502034005001

Sutton RS, Barto AG (1998) Introduction to reinforcement learning. MIT Press, Cambridge

Tajfel H, Turner JC (1986) The social identity theory of intergroup behavior. In: Worchel S, Austin WG (eds) Psychology of intergroup relations. Nelson Hall, pp 276-293

Tiokhin L, Hackman J, Munira S, Jesmin K, Hruschka D (2019) Generalizability is not optional: insights from a cross-cultural study of social discounting. R Soc Open Sci 6(2):181386

Tulving E, Thomson DM (1973) Encoding specificity and retrieval processes in episodic memory. Psychol Rev 80:352-373. https://doi.org/10.1037/h0020071

Varela FJ, Thompson E, Rosch E (1991) The embodied mind: cognitive science and human experience, vol 8. MIT Press, Cambridge

Victor DG (2015) Climate change: embed the social sciences in climate policy. Nature 520:27-29

von Heland J, Folke C (2014) A social contract with the ancestorsculture and ecosystem services in southern Madagascar. Glob Environ Change 24:251-264. https://doi.org/10.1016/j.gloen vcha.2013.11.003

Weber EH (1834) De Pulsu, Resorptione, Auditu et Tactu: Annotationes, Anatomical et Physiological. Koehler, Leipzig
Weber M (1919) Geistige arbeit als beruf: vier vorträge vor dem freistudentischen bund. Vortrag: politik als Beruf, vol 2. Duncker $\&$ Humblot

Weber EU (2003) Perception matters: psychophysics for economists. In: Carrilo J, Brocas I (eds) Psychology and economics. Oxford University Press, Oxford, pp 165-176

Weber EU (2015) Climate change demands behavioral change: what are the challenges? Soc Res Int Q 82:561-581

Weber EU, Johnson EJ (2009) Mindful judgment and decision making. Annu Rev Psychol 60:53-85. https://doi.org/10.1146/ annurev.psych.60.110707.163633

Weber EU, Lindemann PG (2007) From intuition to analysis: making decisions with our head, our heart, or by the book. In: Plessner $\mathrm{H}$, Betsch C, Betsch T (eds) Intuition in judgment and decision making. Erlbaum, Mahwah, NJ, pp 191-208

Weber EU, Ames DR, Blais A-R (2005) 'How Do I Choose Thee? Let me Count the Ways': a textual analysis of similarities and differences in modes of decision-making in China and the United States. Manag Organ Rev 1:87-118. https://doi.org/ 10.1111/j.1740-8784.2004.00005.x

Weber EU, Johnson EJ, Milch KF et al (2007) Asymmetric discounting in intertemporal choice: a query-theory account. Psychol Sci 18:516-523. https://doi.org/10.1111/j.1467-9280.2007.01932.x

Wijermans N, Boonstra WJ, Orach K et al (2020) Behavioral diversity in fishing - towards a next generation of fishery models. Fish Fish 21:872-890. https://doi.org/10.1111/faf.12466

Publisher's Note Springer Nature remains neutral with regard to jurisdictional claims in published maps and institutional affiliations. 